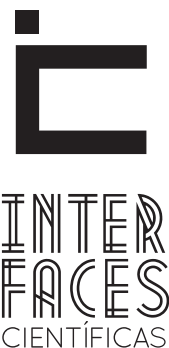

EDUCAÇÃo

ISSN IMPRESSO 2316-333X

ISSN ELETRÔNICO 2316-3828

DOI 10.17564/2316-3828.2016v4n3p139-150

\title{
NO INTERIOR DA SALA DE AULA: AS RELAC̄̃̃ES DE GÊNERO NOS ANOS INICIAIS DO ENSINO FUNDAMENTAL
}

Benedito G. Eugenio ${ }^{1}$

\section{RESUMO}

0 artigo apresenta os resultados de uma pesquisa sobre as relações de gênero na escola. A partir de dados coletados por meio de observações em uma turma dos anos iniciais, problematizamos a maneira pela qual as questões relacionadas a gênero estão presentes no interior da sala de aula a partir da interação estabelecida entre e pelas crianças.

\section{Giulia Boaretto²}

\section{PALAVRAS-CHAVE}

Gênero. Escolar. Crianças. 


\section{ABSTRACT}

The article presents the results of a research on gender relations in school. From data collected through observations in a class of first years, problematize the way in which gender-related issues are present inside the classroom from the interaction between children.

\section{RESUMEN}

El artículo presenta los resultados de una investigación acerca de las relaciones de género en la escuela. Los datos fuera recogidos a través de observaciones en una clase de primero año de la escuela primária y problematiza la forma en que las cuestiones de género están presentes en el aula a partir de la interacción establecida entre los niños.

\section{KEYWORDS}

Gender. School. Children.

\section{PALABRAS-CLAVE}

\author{
Género. Escuela. Niños.
}




\section{INTRODUÇÃO}

Durante muitos anos, gênero e sexo se difundiram como sinônimos, estando relacionados com a produção da existência biológica dos seres humanos.

\author{
Segundo Nicholson (2000, p. 3),
}

Em meados dos anos 60 o termo gênero ainda era uso principalmente como referencias a formas femininas e masculinas dentro da relação ao papel da sociedade na distinção da sociedade entre fenômenos codificados em termos de "masculino" e "feminino". As feministas da segunda fase estenderam o significado do termo para com ele se referir também a muitas das diferenças entre mulheres e homens expostos na personalidade e no comportamento.

De acordo com esta autora, nesse período o termo gênero foi introduzido para suplementar o termo sexo e não para substituí-lo. Somente nos fins dos anos 1960, quando os movimentos feministas emergiram em proporções mundiais, o conceito de gênero foi elaborado e conceituado como uma construção social das identidades sexuais, se dando por meio da dinâmica das relações existentes na sociedade. A dicotomia de sexo e gênero foi se tornando ainda mais evidente e passou-se a diferenciar o ser macho ou ser fêmea (determinação anátomo-fisiológica) do ser homem ou ser mulher (construção social).

Se até a década de 1960 o movimento feminista estava concentrado em questões de ordem social e política, em fins desta década passa a produzir estudos e pesquisas "que tivessem como objetivo não só denunciar, mas, sobretudo, compreender e explicar a subordinação social e a invisibilidade política a que muitas mulheres tinham sido historicamente submetidas" (MEYER, 2003, p. 12).

Importa destacar que em seu início, o movimento feminista prega a igualdade de uma mulher universal (MOREIRA, 2011). As mulheres negras acabam por ser invisibilizada. De acordo com esta autora (2011, p. 60):

\begin{abstract}
A não incorporação da questão racial nas práticas e nas formulações do movimento feminista foi, inicialmente, interpretada como uma prática racista fortemente existente em nossa sociedade. Pode-se dizer que, numa sociedade em que a questão racial ainda é tabu, as conquista do movimento feminista acabam por privilegiar as mulheres brancas em detrimento das negras.
\end{abstract}

Na construção da identidade de gênero, o ser homem ou o ser mulher é influenciado diretamente pelas determinações histórico-culturais de cada sociedade. No caso da sociedade brasileira, desde o período de colonização os homens possuíam liberdade e participação política, enquanto as mulheres assumiam um papel subalterno, cabendo a elas o papel de organização doméstica e cuidados com os filhos.

De acordo com Del Priore (2013, p. 12), no Brasil Colônia,

\footnotetext{
Pobre ou rica, a mulher possuía, porém, um papel: fazer o trabalho de base para todo o edifício familiar- educar os filhos segundo os preceitos cristãos, ensinar-lhes as primeiras letras e atividades, cuidar do sustento e da saúde física e espiritual deles, obedecer e ajudar o marido. Ser, enfim, a "santa mãezinha". Se não o fizesse, seria confundida com um "diabo doméstico". Afinal, sermões difundiam a ideia de que a mulher podia ser perigosa, mentirosa e falsa como uma serpente.
}

Por meio das imposições de uma sociedade patriarcal, eram atribuídos, ainda, às mulheres padrões de condutas e limitações de comportamento, principalmente em relação à sexualidade e à escolha da profissão.

Segundo Del Priore (2011, p. 66), no período imperial havia vários tipos de violência contra as mulheres: física (surras e açoites), abandono, desprezo, malquerer: "Como esposa, seu valor perante a sociedade estava diretamente ligado à 'honestidade' expressa por seu recato, pelo exercício de suas funções no lar e pelos inúmeros filhos que daria ao marido". 
Mudanças significativas vão eclodir nos anos 19601970, com a chamada "revolução sexual". Apesar das grandes mudanças e dos vários avanços conquistados até a contemporaneidade, as expectativas depositadas com relação a homens e mulheres e ocupação dos papéis na sociedade, ainda são diferentes e as mulheres ainda são discriminadas e enfrentam preconceito.

Os modelos de comportamento atuam de forma inconsciente e são transmitidos de geração para geração. Moreno (2003, p. 14) faz uma reflexão significativa acerca do vocabulário adquirido pelo bebê:

O bebê aprende com as primeiras palavras que existe uma "mamãe" e um "papai”; logo aprenderá que existem "meninas" e "meninos”, e esta dicotomia o terá diferenciado muito antes que ele saiba que existe a palavra "pessoa", que pode aplicar-se igualmente a todas elas.

Ou seja, desde a gestação, quando o enxoval é escolhido pelo sexo do bebê - azul para menino e rosa para menina -, perpassando pela aquisição das primeiras palavras, a criança já esta presa às diferenças e imposições que existem nas relações de gênero e, consequentemente, de sexualidades. Aos poucos, ela vai aprendendo que uma menina deve brincar de casinha, de fazer comida, de trocar e alimentar bonecas, enquanto os meninos devem brincar de serem heróis, de lutar, de dirigir carros.

Alem disso, "meninos e meninas aprendem, também desde muito cedo, piadas e gozações, apelidos e gestos para dirigirem àqueles e àquelas que não se ajustam aos padrões de gênero e de sexualidade na sociedade em que vivem" (LOURO, 2000, p. 22). Ao ingressar no ambiente escolar, meninos e meninas já conhecem a sua identidade sexual e os papeis que the são correspondentes.

Reside aí, então, a necessidade de a escola desnaturalizar os preconceitos das mais diversas ordens existentes socialmente. Para isso, é imprescindível o trabalho cotidiano com as diversidades etnicorraciais, de gênero, sexualidades, religiosas, geracionais, dentre outras.
Costa (2008) afirma que a investigação sobre o modo como meninas e meninos expressam as relações de gênero pode contribuir principalmente para a construção de uma sociedade onde independentemente do gênero possa-se expressar de forma livre, tendo seus direitos assegurados e respeitados.

Neste artigo apresentamos os resultados parciais de uma pesquisa acerca das relações de gênero em uma escola dos anos iniciais do ensino fundamental da rede pública do município de Vitória da Conquista-BA.

\section{A PESQUISA COM CRIANÇAS E SUAS CARACTERÍSTICAS}

Para que se possa investigar o modo como meninas e meninos expressam as relações de gênero dentro da escola, é preciso primeiramente compreender as peculiaridades da pesquisa com crianças. Costa (2008, p. 15) pontua que:

Realizar um estudo do cotidiano em uma instituição de educação infantil elegendo a criança como foco, encarar o desafio de dar voz a essas crianças, ouvir de fato suas "cem linguagens" e ainda selecionar dentre essas linguagens as que se referem à construção dos gêneros é uma meta que requer muita disciplina, clareza nos procedimentos, além de muita sensibilidade.

Podemos notar atualmente nas pesquisas brasileiras um esforço teórico-metodológico e o desenvolvimento de estudos para a construção de uma metodologia de pesquisa com criança. Várias áreas do conhecimento têm contribuído para problematizar a concepção de infância como categoria analítica e os aspectos metodológicos que precisam ser considerados para conhecer os diferentes campos e contextos em que as crianças estão inseridas, atuando e interagindo junto aos adultos.

O fazer pesquisa, englobando o universo da infância é um tanto quanto provocador e desafiador. Ao mesmo tempo em que o universo infantil oferece di- 
versas possibilidades de investigação para o campo da educação, tem que se ter consciência de que os sujeitos estudados são marcados pelo seu tempo histórico, sua cultura e sua condição social.

Um aspecto ligado à metodologia da pesquisa, envolvendo crianças que merece destaque é a postura do pesquisador ao entrar no universo infantil. Inicialmente, é necessário que se desvincule totalmente da ideia de que a criança é um adulto em miniatura, e a compreenda como um ser com características próprias, que possui suas ideias e interesses de forma diferente dos adultos. Também é preciso compreender os meios em que os sujeitos estudados estão inseridos e interligá-los ao contexto social, que determina muitas vezes seu comportamento, desejos e formas de expressão.

Ao adentrar ao universo infantil é importante notar que as crianças não expressam seus preconceitos, ideais e vivências apenas por meio de conversas ou quando questionadas. Uma das mais importantes formas de enxergar a criança e perceber como o meio interfere na construção da sua personalidade e da sua relação com as outras pessoas é pelas brincadeiras, que na escola se intensificam ou se restringem ao intervalo.

Reconhecer os diferentes espaços da escola como partes do todo é um dos procedimentos a serem levados em consideração no fazer pesquisa. No momento do intervalo, podemos observar nas brincadeiras do faz-de-conta a expressão dos desejos e vontades das crianças, a experimentação dos diferentes papéis sociais, à forma como visualizam certas situações, como a mãe que é dona de casa e cuida dos filhos e o pai que vai trabalhar como bombeiro. De acordo com Vieira e Cordazzo (2008), nos jogos que de regras as crianças apresentam algumas características que diferem em relação ao sexo, demonstrando muitas vezes as diferenças de gênero.

Por isso, é fundamental que o pesquisador esteja atento a todos os espaços e todas as formas que as crianças vivenciam e se expressam respectivamente. Apro- ximar-se da criança requer um olhar que precisa estar aberto à novidade para os acontecimentos inusitados.

As crianças tendem a ser extremamente observadoras e, ao se deparar com uma pessoa desconhecida em seu espaço, já a diferem dos demais, fazendo seus próprios pré-julgamentos e podendo não agir e se expressar de forma coerente com seu cotidiano. Sendo assim, é importante que o pesquisador se vista, tomando como base as vestes utilizadas pelas pessoas que frequentam o espaço e busque adequar seu vocabulário e comportamento para se integrar à realidade estudada. O fator de identificação contribui para a aproximação do pesquisador com o sujeito; ganhar a confiança da criança para que esta se sinta segura ao expressar-se é de grande relevância.

No estudo realizado, todos os aspectos apontados foram levados em consideração. Para a recolha dos dados, realizamos observações participantes em uma escola do município de Vitória da Conquista-BA, com crianças de uma classe com idade média de sete anos, matriculadas no primeiro ano do ensino fundamental.

\section{UM OLHAR SOBRE A ESCOLA INVESTIGADA}

A Escola selecionada para proceder com o estudo e as observações é uma escola municipal que atende a população pobre de três bairros periféricos da cidade de Vitória da Conquista. A Escola atende cerca de 250 alunos, com idades entre 6 a 14 anos, oferecendo possibilidades de matrícula no período matutino e vespertino.

No ano de 2012, por conta do processo de municipalização das últimas escolas de ensino fundamental da Bahia, a escola foi transferida para a rede municipal de ensino. Isso trouxe problemas, como de falta de verba por causa dos trâmites burocráticos, segundo os responsáveis pela gestão da instituição. A coordenadora pedagógica aponta que a municipalização justifica a inexistência de um Projeto Político-Pedagógico. 
0 espaço utilizado para o intervalo é pequeno e inadequado para acolher todos os alunos, o que faz com que os menores tenham o intervalo em horário diferenciado dos demais alunos. Além do espaço pequeno, constam de forma exposta cadeiras e móveis quebrados e inutilizáveis, o que oferece risco para as crianças, já que alguns objetos são pontiagudos e elas frequentemente correm e jogam bola no mesmo espaço.

No total, são cinco salas de aula, uma cozinha, uma sala em conjunto para direção, coordenação e secretaria, e três banheiros, um para profissionais e os outros dois para os estudantes, um feminino e outro masculino. Nota-se um esforço da direção e da coordenadora para decorar as salas e corredores.

A turma escolhida tem alunos de sete a dez anos e no total foram matriculados 28 alunos, sendo apenas oito meninas. No entanto, nas observações, realizadas duas vezes por semana, a média de presentes foi de 22 a 25 alunos. Compreende-se que nessa idade as crianças estão em processo de formação de ideais e apresentam maior probabilidade de estar tendo o primeiro contato com o espaço escolar, por isso, a sala foi escoIhida, visando relacionar as vivências com os estudos realizados acerca das questões de diversidade nas relações escolares, dando ênfase nas questões de gênero.

Foram realizadas observações duas vezes por semana, ao longo de três meses. Os dias eram escolhidos aleatoriamente e sem aviso prévio, a fim que se pudesse acompanhar o cotidiano escolar em diversas situações, sem que a professora fizesse diferentes planejamentos nos dias da observação.

Como a pesquisa é qualitativa, tem como foco de estudo o processo vivenciado pelos sujeitos, buscou-se realizar observações participantes nas quais se tem a oportunidade de aliar o objeto de estudo ao seu contexto, e não apenas descrever as situações e comportamentos observados. Para alcançar tal objetivo, o primeiro passo foi adentrar a sala de aula, buscando ganhar a confiança das crianças e da professora.
Para não ficar constantemente à vista dos alunos, chamando a atenção e os distraindo durante as atividades, optamos por sentar ao fundo. Os lugares na sala geralmente não eram delimitados para cada criança, exceto em dias de atividades especificas, no entanto, alguns alunos considerados os mais bagunceiros e desatenciosos, três meninos, eram sempre colocados pela professora em uma coluna ao lado da parede. Segundo ela, era uma forma de afastá-los dos outros colegas para que não viessem a atrapalhar a ordem da sala.

Em uma conversa com a professora, a diretora explicou como procederiam aos dias de observação, deixando claro o nosso papel que deveria ser discreto na sala. Mas, a professora nos enxergou como possibilidade de auxílio, nos apresentou para os alunos como "Pró", e sempre que começava a desenvolver uma atividade buscava nos explicar e justificar quaisquer dos seus comportamentos, como por exemplo, não dar um lápis para um dos alunos porque o mesmo não tinha realizado uma determinada atividade do dia anterior. E ainda, em voz alta, no nosso primeiro contato, avisou "Essa turma é hiperativa e têm comportamento complicado".

A sala de aula apresentava uma rotina aparentemente bem definida: assim que as crianças chegavam, trazidas por seus familiares/responsáveis ou transporte escolar, sentavam-se em suas cadeiras e não podiam conversar até todos chegarem para começarem com as atividades. A professora sempre exigia silêncio e que os alunos se mantivessem sentados e virados para frente durante todo o tempo em sala de aula. Mesmo a maioria da sala tendo a oportunidade de escolher o lugar onde gostaria de se sentar, quase todos os dias das observações os alunos estavam sentados nos mesmos lugares ou nas mesmas fileiras, geralmente não migravam para os outros espaços da sala.

No momento da chegada, alguns familiares aproveitavam para conversar com a professora e perguntar sobre o desempenho do aluno ou questionar alguma situação que estivesse ocorrendo, como brigas entre alunos ou apelidos maldosos. Logo depois, a profes- 
sora dava início às atividades. Geralmente, pedia que eles mostrassem a tarefa de casa que havia sido passada no dia anterior e olhava de um em um, sempre elogiando os que cumpriam com os deveres.

Depois, a professora iniciava as atividades como: ditados, cópia do livro ou atividades do livro didático. Às 15h o lanche era oferecido dentro da sala de aula, e assim que eles terminavam, poderiam sair para o pátio para brincar. No momento do lanche a professora também exigia total silêncio; alguns alunos traziam merenda de casa, mas a grande maioria dependia da merenda da escola.

Após voltarem do intervalo, recomeçavam as atividades e iam até as cinco horas da tarde, quando já começavam a se organizar e esperar os familiares ou transporte para voltarem para casa.

Às quintas-feiras a professora tinha o horário para planejamento, e dois monitores eram responsáveis por acompanhar e desenvolver atividades com a turma. Presenciamos dois desses dias, em que notamos que as crianças ficavam "soltas" e as atividades desenvolvidas como pinturas, filmes, eram escolhidos de forma aleatória e sem nenhum planejamento pedagógico, sendo um dia em que os alunos ficavam livres na sala, muitas vezes se agredindo fisicamente.

\section{AS RELAÇÕES DE GÊNERO NO INTERIOR DA SALA DE AULA}

Gênero é aqui compreendido tomando como base as contribuições de Scott (1995, p. 14): "o gênero é um elemento constitutivo das relações sociais fundadas sobre as diferenças percebidas entre os sexos, e o gênero é um primeiro modo de dar significado às relações de poder". Para esta autora, o gênero implica em quatro elementos que funcionam de forma articulada, mas não necessariamente ao mesmo tempo: os símbolos culturalmente disponíveis; os conceitos normativos expressos nas doutrinas científicas, políticas, religiosas, educativas e jurídicas; a fixidez na representação binária do gênero; a identidade subjetiva vinculada ao indivíduo.

Quando estes elementos se articulam, eles acabam por constituir papéis, valores, representações, crenças e relações de poder. A vinculação do gênero ao poder demonstra suas dimensões política, hierárquica e relacional. As relações entre os sexos são socialmente construídas, levando-nos a concluir que o gênero não apresenta uma estrutura fixa.

As relações de gênero estão presentes em todos os contextos da sociedade. Nas observações da turma, ficou evidente o quanto as crianças já chegam à escola, enraizadas de ideias, já construídas, sobre as relações de gênero, delimitando papéis diferentes para homens e mulheres. Observar estas noções já elaboradas e as formas as quais eles se expressam por meio das crianças e da professora é uma tarefa complexa e desafiadora. Pudemos notar que a todo o momento as crianças constroem e reconstroem seus modelos de comportamento, e por isso, acreditamos ainda mais no papel fundamental que a escola exerce para o trabalho com as diferenças.

Um dos aspectos das relações de gênero mais explícitos durante as observações foi a agressividade dos meninos durante as brincadeiras em sala de aula. Enquanto as meninas mantinham-se mais quietas e sentadas em seus lugares, e quando tinham oportunidade conversavam entre si, os meninos em qualquer descuido da professora saíam de suas carteiras e davam início a brincadeiras de chutes, murros e beliscões. Chegamos a presenciar dois meninos se agredindo, em meio a risos, ao ponto de um deles bater com muita força a cabeça do outro contra a parede, o que felizmente não causou nenhuma lesão, mas poderia ter terminado com a hospitalização de um deles.

Nos primeiros meses de vida é praticamente impossivel detectar um nível de agressividade maior em meninos do que nas meninas, mas, à medida que eles 
crescem a diferença vai se acentuando (MORENO, 2003), e quando chegam à escola, podemos perceber claramente como este pressuposto fica em evidência.

Outro aspecto que ainda se constitui como um dos dilemas na educação é a questão da representação de gênero por meio das cores. Nas mochilas dos meninos, a cor que predominava era o azul e o vermelho, enquanto nas mochilas das meninas, o rosa e amarelo eram mais frequentes. Este ponto ficou ainda mais explícito quando em uma das atividades de recorte, assim que a professora distribuiu as tesouras que eram de variadas cores, muitos meninos reclamaram sobre a cor da tesoura que receberam, alegando que "Rosa é cor de menina, eu quero a azul!".

Parece um ponto irrelevante, no entanto, é importante refletirmos nas consequências de pequenas imposições de gênero como essa. Em uma das conversas com uma aluna, ela me relatou que sua cor favorita era o azul, mas que um dos meninos disse que ela deveria gostar de rosa. Ou seja, uma pequena imposição pode acabar impedindo que uma criança expresse sua predileção por não se encaixar nas determinações de uma sociedade que ainda pode ser descrita como machista e preconceituosa.

Em pesquisa realizada numa escola de educação infantil, Eugenio e Mascarenhas (2013, p. 197) apontam que os materiais didáticos e objetos, no caso da instituição investigada, serviam como demarcadores das relações de gênero e que isso se refletia por meio da reprodução das crianças em suas ações:

[...] as cadeiras cor de rosa da sala também recebiam a prioridade das meninas, além de se perceber que as meninas sempre se sentavam com as meninas e os meninos, com os meninos. Dessa forma, as mesas, na grande maioria das observações, eram ocupadas de forma distintas quanto ao gênero.

A mesma aluna que relatou sobre o menino que disse para ela que deveria gostar de rosa, em outra conversa informal contou, em tom de desabafo e tris- teza, que ela é chamada de "tribufu" e de "homenzinho", pela forma como anda e pela voz grossa, e por isso acredita que nunca irá arrumar um namorado porque nenhum menino gosta dela. Essa fala já aponta que a criança compreende que há um padrão de feminilidade/comportamento da mulher a ser seguido.

Percebemos também uma questão muito interessante e digna de questionamento: as diferenças como meninos e meninas expressam a sua sexualidade. Apesar de serem crianças, produzem discursos acerca de namoros e relacionamentos. Enquanto as meninas se expressavam de forma mais acanhada ao falar de namoro, com pequenas brincadeiras de "Você está gostando do menino $x$ da outra turma", ou então até mesmo relatando um namoro, em falas como "Pró, a M.A. estava namorando com o B., mas eles terminaram semana passada".

Os meninos eram mais diretos e, por várias vezes, se referiram a relações sexuais, mesmo que muitas vezes de forma indireta ou até mesmo inconsciente. Em uma das observações, a professora, elogiando um dos meninos, disse: “B. é um menino muito bom”. Em voz baixa apenas para que os colegas mais próximos ouvissem, B, de 11 anos, falou: "Bom mesmo, bom de cama".

No intervalo, as brincadeiras também eram reflexos dos padrões sociais. Pudemos notar que os meninos gostavam de participar de brincadeiras que eles poderiam expressar sua superioridade, sempre desafiando uns aos outros, como em brincadeiras competitivas de "quem corre mais", ou até mesmo futebol, já as meninas no intervalo preferiam ficar sentadas, conversando ou então brincando de pular corda, que não é uma brincadeira competitiva e envolve cooperação de todos. Kishimoto e Ono (2008) afirmam que nas situações lúdicas, os meninos geralmente manifestam maior interesse pelo poder e pelo controle das situações, enquanto as meninas valorizam a imagem do corpo, a beleza dos seres e das coisas e interessam-se pelas atividades domésticas. 
Aproveitando o viés da forma como as meninas cuidam do corpo, por meio das brincadeiras, ficou evidente a preocupação delas com a aparência, optando por brincadeiras que não sujassem a roupa ou ficasse suadas. L. nos explicou que ela e suas amigas não gostavam de correr e nem brincar de futebol porque ficavam "suadas e fedidas". Durante a nossa conversa, vários meninos corriam e jogavam bola, sem demonstrar se importar com o suor.

A professora também expressou seus pré-conceitos e suas generalizações. Um dos primeiros comportamentos que pudemos observar foi em relação às cores da tesoura, situação já relatada, e a professora nos surpreendeu positivamente quando respondeu a um dos estudantes que a cor não determinava de quem era a tesoura, e sim, que todas as tesouras eram de todos os estudantes e que era isso o que importava.

No entanto, poucas semanas depois, a professora começou a questionar o comportamento da sala em voz alta, reclamando dos alunos que não faziam as tarefas e ficavam conversando. Ao tentar explicar o que ela acredita que acontece, a docente repetiu várias vezes que a "culpa" do comportamento das crianças era das mães, que "não sabiam educar". Em vários momentos expressou pensamentos semelhantes, e, sempre atribuindo a mãe a responsabilidade pela educação, descartando a figura paterna.

Carvalho (2000) considera que essa imposição de um modelo particular de família-escola, e de família de papel parental, reforça a tradicional divisão sexual de trabalho na família. Ainda é típico de muitos professores e corpo docente de muitas instituições associarem a responsabilidade pelos filhos muito mais às mães do que aos pais.

Em outra ocasião, enquanto os alunos estavam fazendo uma atividade e a professora já havia pedido silêncio, um dos meninos virou para trás para conversar com o coleguinha que estava sentado e depois permaneceu observando-o. Após alguns minutos a professora falou em tom de deboche, em voz alta: "Vamos L., olhe para frente. Se fosse uma mulher eu até deixava você ficar olhando, mas não sei o que você quer admirando um menino". Esta atitude reforça os papeis destinados a cada um dos sexos. Segundo Louro (1997, p. 58): “A escola delimita espaços. Servindo-se de símbolos e códigos, ela afirma o que cada um pode (ou não pode) fazer, ela separa e institui. Informa o lugar dos pequenos e dos grandes, dos meninos e das meninas".

Há uma vigilância sobre os corpos, os sentimentos, o desejo. De acordo com Louro (2000, p. 21):

\begin{abstract}
As perguntas, as fantasias, as dúvidas e a experimentação do prazer são remetidas ao segredo e ao privado. Através de múltiplas estratégias de disciplinamento, aprendemos a vergonha e a culpa; experimentamos a censura e o controle. Acreditando que as questões da sexualidade são assuntos privados, deixamos de perceber sua dimensão social e política.
\end{abstract}

O fato de uma criança de oito anos, do sexo masculino, admirar outro colega de classe, causa pavor para a professora. A vigilância é exercida como forma de controle sobre o corpo. Há certo pânico com a possibilidade de uma futura relação homoafetiva ser iniciada no espaço da escola. No caso disso ocorrer,

[...] as coisas se complicam ainda mais para aqueles
e aquelas que se percebem com interesses ou dese-
jos distintos da norma heterossexual. A esses restam
poucas alternativas: o silêncio, a dissimulação ou
a segregação. A produção da heterossexualidade é
acompanhada pela rejeição à homossexualidade. Uma
rejeição que se expressa, muitas vezes, por declarada
homofobia. (LOURO, 2000, p. 22).

0 fato da professora, mesmo em tom de brincadeira, repreender um estudante por admirar outro do mesmo sexo, remete-nos à produtividade do poder que, agindo sobre o corpo, resulta na interiorização de normas e regras, fabricando o homem necessário ao funcionamento das instituições. Segundo Camargo (2012, p. 109): 
Com efeito, consciente ou não, o professor exerce o poder disciplinar com seus alunos, na medida em que os induz a serem de determinada forma e não de outra. Por esse motivo é importante estar atento ao exercício do micro poder, pois tudo o que o professor faz com seus alunos é decisão dele. Não se pode esquecer que toda ação é produtora de subjetividades.

Para concluir, a cena descrita anteriormente remete à necessidade de formar os professores para o trabalho com as diferenças. Uma alternativa para se pensar as questões relacionadas a gênero, sexualidade e educação é o filme Minha vida em cor de rosa (Ma vie em rose), de 1997. Nele, Ludovic, de sete anos, vai se dando conta do processo de sua produção identitária, sendo nítido seu sofrimento: por querer ser menina; por conta da violência homofóbica e pela tentativa de imposição da construção de uma masculinidade hegemônica (visível quando seu pai o leva para jogar futebol e fazer coisas de menino). A construção da sexualidade de Ludovic é o fio condutor do filme, evidenciando como família e escola têm dificuldades em lidar com as diferenças.

As várias situações e os diálogos presentes no filme certamente em muito podem contribuir para repensarmos e construirmos outras relações de gênero/ sexualidades no interior da sala de aula, particularmente nos anos iniciais do ensino fundamental.

\section{REFERÊNCIAS}

CAMARGO, Ana M. F. Cultura e diferença no cotidiano da escola e do currículo. In: RIBEIRO, Claudia M. (Org.). Tecendo gênero e diversidade sexual nos currículos da educação infantil. Lavras: UFLA, 2012. p.100-119.

CARVALHO, M. E. P. de. Relações entre família e escola e suas implicações de gênero. Cadernos de Pesquisa, n.110, 2000.

CORDAZZO, S. T. D; VIEIRA, M. L. Caracterização de brincadeiras de crianças em idade escolar.
Psicologia Reflexão Crítica, v.22, n.3, Porto Alegre, 2008. p.365-373.

COSTA, A. de. Cenas de meninas e meninos no cotidiano institucional da educação infantil: um estudo sobre as relações de gênero. 2004 . 157f. Dissertação (Mestrado em Educação) Programa de Pós- Graduação em Educação, Universidade Federal de Santa Catarina, Florianópolis-SC, 2004.

\section{DEL PRIORE, Mary. Histórias íntimas:}

sexualidade e erotismo na história do Brasil. São Paulo: Planeta, 2011.

\section{DEL PRIORE, Mary. Histórias e conversas de mulher.} São Paulo: Planeta, 2013.

EUGENIO, Benedito G.; MASCARENHAS, Eliane R. Relações de gênero em uma escola de educação infantil em Vitória da Conquista. In: DIAS, Alfrâncio; PACHECO, Ana C. (Org.). Gênero multi e transdisciplinar. Jundiaí: Paco, 2013.

KISHIMOTO, T. M; ONO, A. T. Brinquedo, gênero e educação na brinquedoteca. Pró-Posições, v.19, n.3, 2008.

LOURO, Guacira. Gênero, sexualidade e educação: uma perspectiva pós-estruturalista. Petrópolis: Vozes, 1997.

LOURO, Guacira. Pedagogia da sexualidade. In: LOURO, Guacira. (Org.). 0 corpo educado: pedagogias da sexualidade. Belo Horizonte: Autêntica, 2000. p.7-34

MEYER, Dagmar E. Gênero e educação: teoria e política. In: LOURO, G.; NECKEL, J.F.; GOELLNER, S.V. (Org.). Corpo, gênero e sexualidade: um debate contemporâneo na educação. Petrópolis: Vozes, 2003. p.9-27. 
MOREIRA, Núbia R. A organização das feministas negras no Brasil. Vitória da Conquista: UESB, 2011.

MORENO, M. M. Como se ensina a ser menina - o sexismo na escola. Campinas-SP: Universidade Estadual de Campinas, 1999.
NICHOLSON, Linda. Interpretando o gênero. Revista Estudos Feministas, v.8, n.2, 2000.

SCOTT, J. Gênero: uma categoria útil de análise histórica. Educação e Realidade, v.20, n.2, 1995. 
1. Doutor em Educação - UNICAMP. Professor Adjunto da Universidade Estadual do Sudoeste da Bahia-Campus de Vitória da Conquista. Docente do Programa de Pós-Graduação em Relações Étnicas e Contemporaneidade. E-mail: dodoeugenio@yahoo.com.br

2. Discente do curso de Pedagogia da Universidade Estadual do Sudoeste da Aceito em: 20 de abril de 2015 